\title{
Repetition priming endurance in picture naming and translation: Contributions of component processes
}

\author{
Wendy S. Francis and Silvia P. Sáenz \\ University of Texas at El Paso, El Paso, Texas
}

\begin{abstract}
The processes contributing to the durability of repetition priming in picture naming and its decline across a week were assessed in two experiments with Spanish-English bilinguals. In Experiment 1, both picture identification and word retrieval processes of picture naming exhibited facilitation after a week. Word retrieval priming declined substantially relative to a 10-min retention interval, but picture identification priming remained stable. In Experiment 2, word translation exhibited repetition priming after a week. Decreased word retrieval priming accounted for the attenuation of translation priming relative to a 10-min interval, whereas word comprehension priming remained stable. A linear process model was used to formalize and test key hypotheses and to clarify the influences of component processes and retention interval on repetition priming.
\end{abstract}

Scientific understanding of human memory processes has often been advanced by the examination of qualitative and quantitative changes in memory performance across shorter and longer retention intervals. The time course of memory performance puts constraints on explanatory mechanisms. For example, repetition priming effects lasting for several days or weeks are inconsistent with the idea that they are based on temporary activation (Schacter, 1987), a popular explanation in the 1980s (e.g., Graf \& Mandler, 1984; Morton, 1979). More specifically, facilitation for naming repeated pictures relative to new pictures is substantial even after several weeks and therefore cannot be based solely on residual activation from the initial exposure (Cave, 1997; Mitchell \& Brown, 1988; Mitchell, Brown, \& Murphy, 1990); instead, such effects reflect sustained learning based on a single experimental episode. The finding that people with global amnesia and age-matched controls show comparable levels of facilitation in naming repeated pictures at 2- and 7-day intervals also indicates that this repetition priming effect and its retention across time do not require support from explicit memory (Cave \& Squire, 1992).

Since Ebbinghaus's (1885) pioneering experiments, it has been known that forgetting generally occurs rapidly at first and slows over time. Consistent with the patterns of performance observed in more traditional tests of explicit memory and savings, studies of repetition priming in picture naming also suggest a rapid drop in facilitation at first, and then a slower loss of facilitation over time (Brown, Jones, \& Mitchell, 1996; Cave, 1997; Cave \& Squire, 1992; Mitchell \& Brown, 1988; Mitchell et al., 1990). Various mechanisms that might lead to this type of aggregate forgetting function have been evaluated in the context of explicit memory (Wickens, 1998; Wixted, 2004). One possibility is that a set of items with heterogeneous exponential forgetting rates would, in the aggregate, appear as a power function. However, Wixted makes a strong case that the variability required in the forgetting rates is so large as to make a heterogeneous exponential-decay explanation implausible in the context of results that demonstrate that vastly different item types show similar decay rates, once encoded. He concludes that the best supported mechanism underlying the form of the forgetting function is that the longer any item is retained in memory, the less likely it is to be lost in the next unit of time, a conclusion consistent with neuroscientific theories of memory consolidation.

Within the context of repetition priming, we explore a variant of the item-variability explanation, which we will call a process-variability explanation. Repetition priming in a complex task, such as picture naming, derives from the speeding of multiple processes (see the next section). These processes may be regarded as qualitatively different from one another and may exhibit different decay rates following a learning episode. The aggregate function would then show rapid decay at first and slower decay over time as an artifact of the combination of processes that have faster and slower decay rates. Therefore, priming at shorter intervals would reflect both slow and fast decaying processes, but priming at longer intervals would depend more on the slow decaying processes. In the present study, we did not attempt to evaluate the form of the forgetting function, but rather evaluated whether rates of loss for component processes of picture naming and word translation differed across fixed intervals, from $10 \mathrm{~min}$ to 1 week. Similarly, the relative contributions of component

W. S. Francis, wfrancis@utep.edu 
processes in picture naming and translation are evaluated at different retention intervals.

\section{Processes in Picture Naming and Translation}

Both picture naming and translation are complex tasks that require multiple cognitive processes to complete. Picture naming requires, at a minimum, identification of the pictured object, retrieval of the word that names the object, and overt articulation of the corresponding phonology; existing models are in agreement about the necessity of these three types of processes and the order of their initiation (Johnson, Paivio, \& Clark, 1996). Object identification processes are usually considered to include access to amodal concepts (Levelt, 1989; Potter, So, von Eckardt, \& Feldman, 1984; Snodgrass, 1984; Theios \& Amrhein, 1989). Previous research has provided strong evidence that picture naming is concept mediated in monolinguals (Durso \& Johnson, 1979; Potter \& Faulconer, 1975; Smith \& Magee, 1980) and in fluent bilinguals (Chen \& Leung, 1989; Francis, Augustini, \& Sáenz, 2003; Francis et al., 2002; Kroll \& Stewart, 1994; Potter et al., 1984; Sholl, Sankaranarayanan, \& Kroll, 1995). For the purposes of the present study, the component processes of picture naming are intentionally oversimplified by division into two sets of processes: (1) picture identification, which includes perceptual processes and retrieval of the concept; and (2) word retrieval, which includes selecting of the appropriate word and phonology, as well as articulating the overt verbal response.

The processes of translation have been explored in several bilingual experiments. There is a consensus that translation from the dominant to the nondominant language is concept mediated in fluent bilinguals (e.g., Chen \& Leung, 1989; Kroll \& Stewart, 1994; Potter et al., 1984; Sholl et al., 1995). Translation from the nondominant to the dominant language is also concept mediated in fluent bilinguals by most accounts (e.g., De Groot \& Poot, 1997; Francis, Augustini, \& Sáenz, 2003; La Heij, Hooglander, Kerling, \& van der Velden, 1996; Miller \& Kroll, 2002), although a few studies suggest that conceptual access is not necessary (Kroll \& Stewart, 1994; Sholl et al., 1995). As with picture naming, the component processes in concept-mediated translation will be simplified by division into two sets of processes: (1) word comprehension, which includes perceptual processes and retrieval of the concept; and (2) word retrieval in the target language, which again includes selecting the appropriate word and phonology and articulating the response.

These task analyses beg the question whether the word retrieval processes in picture naming and word translation are one and the same; our previous research with bilinguals suggests this to be the case. Fluent bilinguals showed substantial and symmetric repetition priming between picture naming and translation tasks that had the same response language, with stronger facilitation in the nondominant language (Francis, Augustini, \& Sáenz, 2003).

\section{Components of Priming in Picture Naming and Translation}

Any of the processes in picture naming or translation that are not overlearned may benefit from repetition. The contribution of picture identification processes to repetition priming in picture naming has been demonstrated using encoding tasks that require accessing conceptual information about pictures. Decisions about the animacy, weight, natural versus manufactured origin, or category membership of a pictured object facilitate later naming relative to new items (Carroll, Byrne, \& Kirsner, 1985; Francis et al., 2002; Vaidya et al., 1998). In bilinguals, prior naming of pictures in a different language facilitates naming relative to new items (Francis, 1998; Francis, Augustini, \& Sáenz, 2003; Francis et al., 2002; Hernandez \& Reyes, 2002). The contribution of word retrieval processes to repetition priming in picture naming has been demonstrated using encoding tasks that require selecting and/or articulating the name without presentation of the target picture. Picture naming was facilitated by generating a picture's name in response to a definition (Lee \& Williams, 2001; Monsell, Matthews, \& Miller, 1992; Wheeldon \& Monsell, 1992), in response to a different exemplar of the object (Biederman \& Cooper, 1991; Cave, Bost, \& Cobb, 1996; Cave \& Squire, 1992; Durso \& Johnson, 1979; Francis et al., 2002; Stankiewicz, Hummel, \& Cooper, 1998), or as a translation response (Francis, 1998; Francis, Augustini, \& Sáenz, 2003; Francis et al., 2002).

Like picture naming, word translation also exhibits repetition priming effects at delays of several minutes (Francis et al., 2002; Francis \& Durán, 2005; Francis \& Gallard, 2005; Francis, Tokowicz, \& Kroll, 2003), but translation priming has not previously been measured at longer retention intervals. A long-term repetition priming effect for translation would indicate that a single experimental translation trial can lead to sustained learning and that this facilitation cannot be attributed to residual activation. Evidence for a word comprehension component in translation priming comes from studies in which translation was facilitated by prior semantic categorization of the stimulus word (Francis et al., 2002), drawing a picture to represent the stimulus word (Francis \& Durán, 2005), or translation of the stimulus word into a neutral third language (Francis \& Gallard, 2005). Evidence for a word retrieval component in translation priming comes from studies in which translation was facilitated by prior picture naming (Francis, Augustini, \& Sáenz, 2003; Francis et al., 2002; Francis \& Durán, 2005; Sholl et al., 1995) or by prior translation from a neutral third language (Francis \& Gallard, 2005).

\section{Transfer-Appropriate Processing Logic}

In the present study, inferences about contributions of component processes to repetition priming were derived from a fundamental application of transfer-appropriate processing logic. According to the transfer-appropriate processing principle (Morris, Bransford, \& Franks, 1977; Roediger \& Blaxton, 1987), the degree of transfer or priming from study to test depends on the similarity of the cognitive processes involved in the study and test tasks. We derived predictions from a specific interpretation of transfer-appropriate processing, in which common cognitive processes between study and test tasks are treated as the causal basis of facilitation. Processes are defined in terms of mental operations completed, not of levels of 
Table 1

Model of Repetition Priming Effects: Shared Processes, Priming, and Parameter Estimates

\begin{tabular}{|c|c|c|c|c|c|c|c|c|c|}
\hline \multirow{3}{*}{$\begin{array}{c}\text { Task } \\
\text { (Encoding } \rightarrow \text { Test) } \\
\end{array}$} & \multicolumn{5}{|c|}{ Shared Processes } & \multicolumn{4}{|c|}{ Repetition Priming (msec) } \\
\hline & \multirow[b]{2}{*}{ PI } & \multirow{2}{*}{$\begin{array}{l}\text { WC } \\
\text { in L1 }\end{array}$} & \multirow{2}{*}{$\begin{array}{l}\text { WC } \\
\text { in } \mathrm{L} 2\end{array}$} & \multirow{2}{*}{$\begin{array}{l}\text { WR } \\
\text { in L1 }\end{array}$} & \multirow{2}{*}{$\begin{array}{l}\text { WR } \\
\text { in L2 }\end{array}$} & \multicolumn{2}{|c|}{ Observed } & \multicolumn{2}{|c|}{ Model } \\
\hline & & & & & & $\mathrm{Imm}$. & Del. & Imm. & Del. \\
\hline \multicolumn{10}{|l|}{ Experiment 1} \\
\hline PN1 $\rightarrow$ PN1 & $\mathrm{X}$ & & & $\mathrm{X}$ & & 242 & 184 & 248 & 190 \\
\hline $\mathrm{PN} 2 \rightarrow \mathrm{PN} 1$ & $\mathrm{X}$ & & & & & 116 & 111 & 97 & 97 \\
\hline $\mathrm{TR} 21 \rightarrow \mathrm{PN} 1$ & & & & $\mathrm{X}$ & & 161 & 122 & 151 & 92 \\
\hline $\mathrm{PN} 2 \rightarrow \mathrm{PN} 2$ & $\mathrm{X}$ & & & & $\mathrm{X}$ & 355 & 248 & 341 & 246 \\
\hline $\mathrm{PN} 1 \rightarrow \mathrm{PN} 2$ & $\mathrm{X}$ & & & & & 111 & 95 & 97 & 97 \\
\hline $\mathrm{TR} 12 \rightarrow \mathrm{PN} 2$ & & & & & $\mathrm{X}$ & 247 & 153 & 243 & 149 \\
\hline \multicolumn{10}{|l|}{ Experiment 2} \\
\hline $\mathrm{PN} 1 \rightarrow \mathrm{PN} 1$ & $\mathrm{X}$ & & & $\mathrm{X}$ & & 237 & 179 & 248 & 190 \\
\hline $\mathrm{PN} 2 \rightarrow \mathrm{PN} 2$ & $\mathrm{X}$ & & & & $\mathrm{X}$ & 330 & 230 & 341 & 246 \\
\hline TR21 $\rightarrow$ TR21 & & & $\mathrm{X}$ & $\mathrm{X}$ & & 299 & 247 & 302 & 244 \\
\hline TR12 $\rightarrow$ TR12 & & $\mathrm{X}$ & & & $\mathrm{X}$ & 336 & 244 & 337 & 243 \\
\hline \multicolumn{10}{|l|}{ Parameter Estimates } \\
\hline \multicolumn{10}{|l|}{ Full Model } \\
\hline Contribution & 103 & 94 & 155 & 145 & 242 & & & & \\
\hline Forgetting & .12 & .00 & .06 & .30 & .38 & & & & \\
\hline \multicolumn{10}{|l|}{ Restricted Model } \\
\hline Contribution & 97 & 94 & 152 & 151 & 243 & & & & \\
\hline Forgetting & $.00^{*}$ & $.00^{*}$ & $.00^{*}$ & $.39^{\dagger}$ & $.39^{\dagger}$ & & & & \\
\hline
\end{tabular}

Note-PI, picture identification; WC, word comprehension; WR, word retrieval; L1, dominant language; L2, nondominant language; Imm., immediate; Del., delayed; PN1 and PN2, picture naming in L1 and L2, respectively; TR21 and TR12, translation of L2 to L1 and L1 to L2, respectively. X indicates processes shared by the study and test tasks; model values for priming effects are those obtained in fitting the 6-parameter restricted model. ${ }^{*}$ These parameters were set to zero. †These parameters were set equal.

representation activated; repetition of these processes is assumed to strengthen the links, or connectivity, between mental representations. This version of transfer-appropriate processing is similar to those used by other researchers to derive predictions about repetition priming (Monsell et al., 1992; Sholl et al., 1995; Stankiewicz et al., 1998). ${ }^{1}$ However, we take this logic a few steps farther by making the basis for deriving predictions more explicit.

Tasks are defined in terms of their component processes, and the processes are conceptualized as they are in "critical path networks" (Townsend \& Schweickert, 1989) and other mathematical models of picture and word processing (e.g., Theios \& Amrhein, 1989). First, a process is defined in terms of its start and end points and the path taken between them, all of which must match, for two processes to be considered equivalent. In this approach, only the path is used to predict priming. Prior practice of processes necessary to complete a test task elicits a decrease in response time (RT) as concluded by Franks, Bilbrey, Lien, and McNamara (2000), so long as the practiced process or processes are not overlearned (in which case there would be no detectable practice effect). Practice of a subset of processes necessary for completion of the test task exerts a selective facilitating influence on those processes when the item is repeated, resulting in a corresponding decrease in completion time.

Each experiment in this study consisted of a set of repetition conditions meant to facilitate picture identification, word comprehension, word retrieval, or a combination of these processes. The use of bilingual materials allows the application of two labels to the same concept, which in turn facilitates isolation and selective influence of identification, comprehension, and production processes. Evidence that translation equivalents for concrete words access the same conceptual representation is well established in the literature (see Francis, 1999, 2005, for extensive reviews). Experiment 1 tests the extent to which picture identification and word retrieval components of priming in picture naming survive or decay across a 1-week retention interval relative to a 10-min interval, using a strategy of selective influence. Experiment 2 measures the extent to which repetition priming of picture naming and translation survive or decay across a 1-week interval relative to a 10 -min interval. The results of the two experiments are combined in a simple model to estimate how much the component processes of translation contribute to priming and to decrements in priming across the retention interval.

The simplicity of the task analyses for picture naming and translation along with the straightforward interpretation of transfer-appropriate processing allow for the critical hypotheses to be expressed in a simple linear model. The priming contributions of the component processes in each experimental condition were expressed in a linear equation. Table 1 shows the processes shared by the encoding and test tasks in each experimental condition. For example, when the encoding task is translation from the dominant to the nondominant language, and the test task is picture naming in the nondominant language, word retrieval processes in the nondominant language are shared. We assume that the processes common to the study and test tasks do not change as a function of retention interval. However, the impact of process repetition on perfor- 


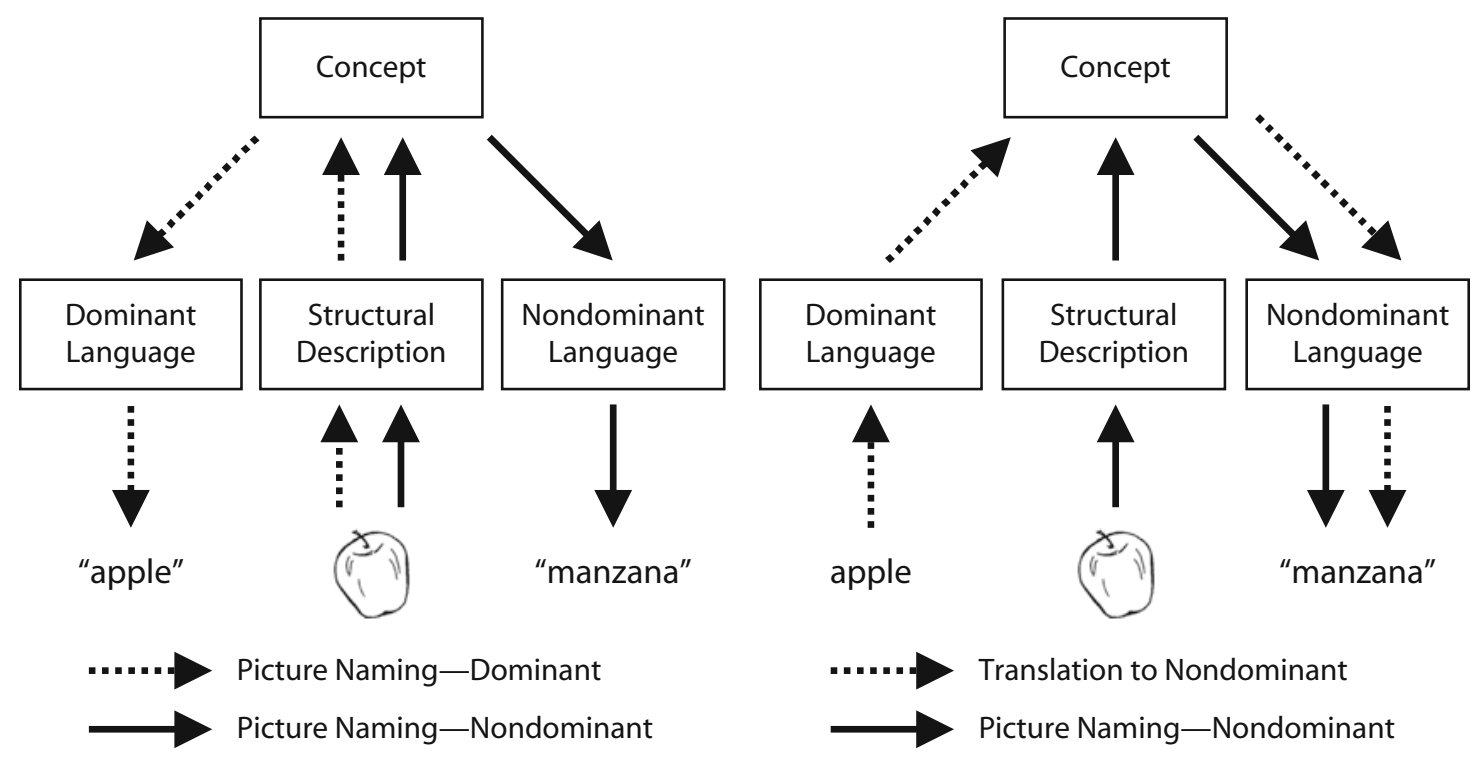

Figure 1. Logic of Experiments 1 and 2. Picture naming in the dominant language and picture naming in the nondominant language share picture identification processes. Picture naming in the nondominant language and translation to the nondominant language share word retrieval processes. Quotation marks indicate overt responses. Graphic from "Repetition Priming in Picture Naming and Translation Depends on Shared Processes and Their Difficulty: Evidence From Spanish-English Bilinguals," by W. S. Francis, B. K.Augustini, and S. P. Sáenz, 2003, Journal of Experimental Psychology: Learning, Memory, \& Cognition, 29, p. 1286. Copyright 2003 by APA. Reprinted with permission.

mance is expected to change as a function of retention interval. The effects of process repetition on performance were measured at 10-min and 1-week retention intervals in two experiments. Experiment 1 contained the 6 conditions necessary to test contributions of picture identification and word retrieval processes to repetition priming in picture naming. Experiment 2 contained the 4 additional conditions necessary to test contributions of word comprehension and word retrieval processes in word translation when combined with the results of Experiment 1 in the model. The model was used to first test whether the relations previously found at short retention intervals hold after a 1-week retention interval. Further tests using restricted versions of the model examined whether a 1 -week delay between encoding and test had differential effects on the component processes contributing to repetition priming in picture naming and translation.

\section{EXPERIMENT 1}

Experiment 1 assessed the relative contributions of picture identification and word retrieval to picture naming facilitation at 10-min and 1-week retention intervals. As illustrated in Figure 1, the encoding task used to facilitate picture identification was picture naming in a different language. For example, naming a picture of an apple in English at encoding and naming the same picture in Spanish at test both require identification of the same pictured object. The encoding task used to facilitate word retrieval was translation to the target language. For example, translating apple to Spanish at encoding and naming a picture of an apple in Spanish at test both require retrieving and articulating the Spanish word manzana. Both tasks have been shown to facilitate later picture naming at a short retention interval, and their facilitating effects appear to be independent (Francis, 1998; Francis, Augustini, \& Sáenz, 2003; Francis et al., 2002). An identical picture naming condition was included for comparison.

\section{Method}

Participants. The participants were 84 Spanish-English bilinguals (43 men, 41 women) ranging in age from 17 to 46 (median, 19), all reporting Hispanic ethnicity (except 1 who did not report ethnicity information). All were undergraduate students at the University of Texas at El Paso who participated for an introductory psychology research requirement, or for a payment of $\$ 5$ per session. None had previously participated in an experiment involving the critical picture stimuli. Twenty-three additional individuals began the protocol, but 12 were excluded because they failed to show up for the second session and 11 were excluded because of low accuracy (less than 50\%) in English or Spanish.

According to the self-report questionnaire, $90.5 \%$ of the participants had learned Spanish first, 5.9\% had learned English first, and 3.6\% had learned Spanish and English simultaneously from early childhood. The median age at which participants had begun to learn their second language was 6 . According to self-ratings of relative proficiency, $51.2 \%$ were classified as English dominant and $48.8 \%$ as Spanish dominant. Because El Paso, TX is located on the U.S.Mexico border and is a bilingual environment, the regular use of both English and Spanish is common. Participants reported that over the preceding month, they had used English $42.5 \%$ of the time, Spanish $43.5 \%$, and a mixture of both languages the remaining $14 \%$.

Apparatus. Stimuli were presented on the monitor of a Macintosh G4 computer, and the sequence and timing of presentation was programmed using PsyScope software (Cohen, MacWhinney, Flatt, $\&$ Provost, 1993). Vocal RTs were collected by means of a PsyScope button box (New Micros, Dallas, TX) with a high-impedance microphone attached.

Stimuli. The 280 picture stimuli were selected primarily from the Snodgrass and Vanderwart (1980) normed picture set and the 
Table 2

Encoding Phase Response Times (RT, in Milliseconds) and Error Rates (\%) in Experiments 1 and 2

\begin{tabular}{cccccc}
\hline & \multicolumn{3}{c}{ RT } & & \multicolumn{2}{c}{ Error Rate } \\
\cline { 2 - 3 } Task & L1 & L2 & & L1 & L2 \\
\hline & \multicolumn{2}{c}{ Experiment 1 } & & \\
Picture naming & 1,050 & 1,225 & & 10.1 & 20.7 \\
Translation & 1,229 & 1,230 & & 16.3 & 21.6 \\
& \multicolumn{2}{c}{ Experiment 2 } & & \\
Picture naming & 1,064 & 1,201 & & 9.8 & 22.6 \\
Translation & 1,235 & 1,246 & & 16.0 & 22.6 \\
\hline
\end{tabular}

Note-For translation, the language indicated is the response language, not the stimulus language. L1, dominant language; L2, nondominant language.

Pictures Please library (Abbate, 1984). The names of the pictures had a mean letter length of 5.6 in English and 6.4 in Spanish, and the median frequency in the written English was 14 per million (Kučera $\&$ Francis, 1967). Although none of the items had names with identical spelling or pronunciation in English and Spanish, 26\% could potentially be considered cognates (e.g., cross/cruz or stove/estufa). ${ }^{2}$ The stimuli were randomly assigned to 14 sets of 20 items. The sets were rotated through the experimental conditions across participants using a Latin square to control for specific-item effects.

Design. The experiment had a 3 (encoding task) $\times 2$ (response language) $\times 2$ (retention interval) within-subjects factorial design, with an additional new-item control condition in each language. Thus, there were 14 conditions in all. The encoding tasks were picture naming in the target language, picture naming in the nontarget language, and translation to the target language. The final response language was English for half the items and Spanish for half the items. The retention interval between prime trial and test trial was approximately $10 \mathrm{~min}$ for items in the immediate condition and 1 week for items in the delayed condition. The primary dependent variable was $\mathrm{RT}$ in test phase picture naming.

Procedure. Participants were tested individually by a bilingual experimenter in two 30-min sessions spaced a week apart. In the first session, participants completed encoding tasks for all items assigned to the delayed condition. There were 4 blocks of trials corresponding to the tasks of picture naming in English, picture naming in Spanish, translation from English to Spanish, and translation from Spanish to English. Instructions for these tasks were given in the assigned response language. Each block began with 3 practice trials and continued with the experimental trials ( 40 for picture naming blocks and 20 for translation blocks). On each trial, the stimulus appeared on the screen and remained until a vocal response was registered; after a 1,250-msec intertrial interval, the next stimulus appeared. The experimenter noted unexpected responses and timing errors on a preprinted list of expected responses. After completing the naming and translation tasks, participants filled out a language background questionnaire.

In the second session, participants completed the encoding tasks for the immediate condition. The test phase immediately followed. In the test phase, all experimental pictures were named. The English and Spanish picture-naming blocks each consisted of 140 trials with a short rest halfway through. Languages and task order were counterbalanced across participants but kept consistent for the encoding and test phases of any individual.

\section{Results}

Data processing. Because analysis focused on RTs in the test phase of the experiment, invalid test phase trials were removed before extracting the condition means for each participant. Out of a total of 280 test phase trials, on average $12.1 \%(S D=5.5 \%)$ were removed as naming response errors (including don't know responses), 1.0\% were removed as machine timing errors, and $12.6 \%$ were removed as spoiled trials. Spoiled trials had correct and correctly timed test phase responses, but the prime status of the item was compromised. Trials were considered spoiled if the encoding phase response was unacceptable $(8.4 \%)$, was acceptable but inconsistent with the test phase response $^{3}(1.6 \%)$, or had a machine timing error $(1.2 \%)$, or if the answer or its translation was given as an error response to an earlier item (1.4\%). Items with RTs greater than 5,000 msec, less than $200 \mathrm{msec}$, or more than 2 standard deviations from the condition mean were removed as outliers, thus excluding $4.5 \%$ of the trials. On average, $69.7 \%$ of the test phase trials were retained for the RT analysis, a mean of 14 items per condition per participant.

Encoding phase. Encoding phase response times and error rates are shown in Table 2 as a function of the task and response language. Because approximately half of the participants reported dominance in each language, and language proficiency is known to affect RTs, error rates, and repetition priming, English and Spanish responses were recoded in terms of the dominant and nondominant languages for all analyses. Encoding phase RTs and error rates were analyzed using separate 2 (task) $\times 2$ (response language) repeated measures ANOVAs. All inferential statistics were bidirectional with $\alpha=.05$. Overall, RTs were faster for picture naming than for translation $[F(1,83)=$ $\left.29.45, M S_{\mathrm{e}}=24,119, p<.001\right]$, and responses in the dominant language were faster than in the nondominant language $\left[F(1,83)=25.64, M S_{\mathrm{e}}=25,362, p<.001\right]$. The advantage for the dominant language was stronger for picture naming, as indicated by a significant interaction $\left[F(1,83)=33.36, M S_{\mathrm{e}}=19,379, p<.001\right]$. Error rates exhibited the same pattern, with more errors in translation $\left[F(1,83)=32.21, M S_{\mathrm{e}}=.0033, p<.001\right]$, and in the nondominant language $\left[F(1,83)=68.05, M S_{\mathrm{e}}=\right.$ $.0079, p<.001]$. The effect of response language on error rates was stronger for picture naming than for translation $\left[F(1,83)=16.09, M S_{\mathrm{e}}=.0037, p<.001\right]$.

Test phase. Test phase RTs and error rates are shown in Table 3 as a function of encoding condition, response language, and retention interval. Picture naming RTs for new items were faster in the dominant language than in the nondominant language $[t(83)=4.19, p<.001]$. Priming was measured by subtracting the mean RTs for items in the repeated conditions from the mean RTs for new items named in the same language. Priming effects are illustrated in Figure 2 as a function of encoding condition, language, and retention interval. Using a Bonferroni correction with a family-wise error rate of $\alpha=.05$, priming effects in all 12 conditions were statistically significant.

The subtracted priming scores were analyzed using a 3 (encoding condition) $\times 2$ (response language) $\times 2$ (retention interval) repeated measures ANOVA. The priming magnitude differed across encoding conditions $[F(2,166)=$ 79.83, $\left.M S_{\mathrm{e}}=23,635, p<.001\right]$. Planned comparisons showed that priming was greater in the identical condition than in the translation condition $\left[F(1,83)=85.23, M S_{\mathrm{e}}=\right.$ $29,794, p<.001]$, and greater in the translation condition than in the different language condition $[F(1,83)=19.86$, 
Table 3

Test Phase Picture Naming Response Times (RT, in Milliseconds) and Error Rates (\%) in Experiment 1

\begin{tabular}{|c|c|c|c|c|}
\hline \multirow[b]{2}{*}{ Encoding Task } & \multicolumn{2}{|c|}{ RT } & \multicolumn{2}{|c|}{ Error Rate } \\
\hline & L1 & L2 & L1 & L2 \\
\hline New Items & 1,214 & 1,365 & 9.2 & 18.2 \\
\hline \multicolumn{5}{|l|}{ Immediate Retention Interval (10 min) } \\
\hline Picture naming-same language & 971 & 1,010 & 6.5 & 15.2 \\
\hline Picture naming-different language & 1,097 & 1,254 & 8.2 & 18.5 \\
\hline Translation to response language & 1,053 & 1,118 & 7.3 & 14.7 \\
\hline \multicolumn{5}{|l|}{ Delayed Retention Interval (1 week) } \\
\hline Picture naming-same language & 1,030 & 1,117 & 7.7 & 14.5 \\
\hline Picture naming-different language & 1,103 & 1,270 & 7.6 & 17.9 \\
\hline Translation to response language & 1,092 & 1,212 & 8.2 & 15.7 \\
\hline
\end{tabular}

Note-The test task was picture naming in all conditions. L1, dominant language; L2, nondominant language.

$\left.M S_{\mathrm{e}}=65,577, p<.001\right]$. The main effect of response language was not significant $\left[F(1,83)=2.81, M S_{\mathrm{e}}=185,250\right.$, $p=.098]$; however, the interaction of response language and encoding condition was significant $[F(2,166)=10.08$, $\left.M S_{\mathrm{e}}=21,700, p<.001\right]$. Specifically, priming in the identical and translation conditions was stronger when responding in the nondominant language than in the dominant language, but priming in the different-language naming condition did not depend on the response language.

The effects of the delay on priming are summarized in Figure 3. Overall, priming was attenuated across the delay, as indicated by a main effect of retention interval $\left[F(1,83)=29.21, M S_{\mathrm{e}}=24,599, p<.001\right]$. This attenuation was substantial (and of similar magnitude) for the identical and translation conditions but not for the different-language picture naming condition; the interaction of retention interval and encoding condition was significant $\left[F(2,166)=4.39, M S_{\mathrm{e}}=27,392, p=.014\right]$. The attenuation of priming across the delay was stronger when final responses were given in the nondominant language $\left[F(1,83)=4.23, M S_{\mathrm{e}}=21,634, p=.043\right]$. The three-way interaction of encoding condition, language, and reten- tion interval was not significant $\left[F(2,166)=0.71, M S_{\mathrm{e}}=\right.$ $17,176, p=.493]$.

\section{Discussion}

Priming was significant but attenuated after a 1-week delay in identical repetition conditions, as in previous studies (Brown et al., 1996; Cave \& Squire, 1992; Mitchell \& Brown, 1988). Both picture identification and word retrieval processes contribute to the durability of priming across long retention intervals, as indicated by the significant priming in all conditions after a 1-week delay. However, the attenuation of priming across the delay appeared to occur exclusively in word retrieval. Priming due to picture identification processes did not decrease across the delay. In contrast, priming in conditions in which word retrieval processes were repeated from encoding to test decreased substantially, with similar effects for the identical and translation conditions. This pattern cannot be explained simply as a function of the relative magnitudes of priming in the three encoding conditions.

Both repetition of picture identification processes and repetition of word retrieval processes elicited facilitation

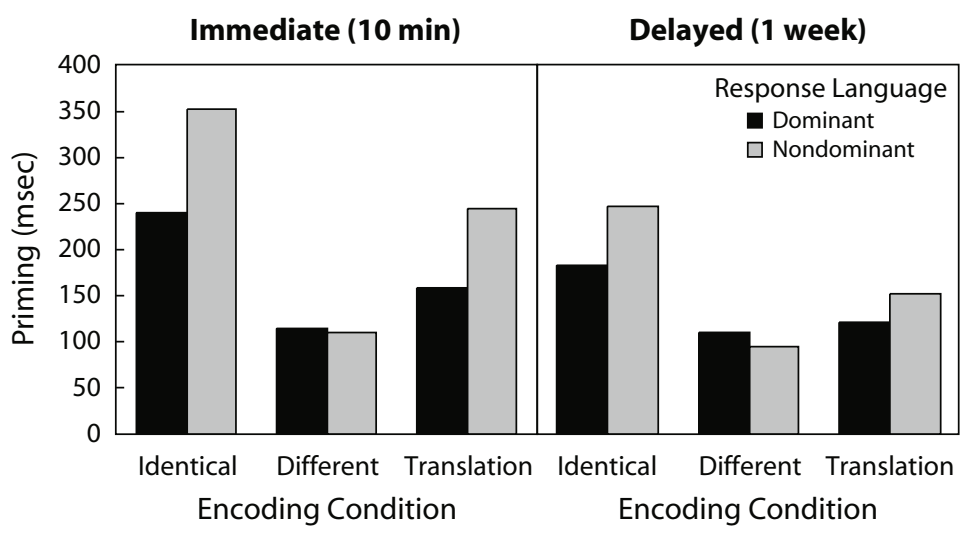

Figure 2. Priming effects in Experiment 1 as a function of retention interval, encoding task, and response language. Priming is measured relative to new item picture naming response times in the test phase. Identical, picture naming in the target language; Different, picture naming in the nontarget language; Translation, translation to the target language. 


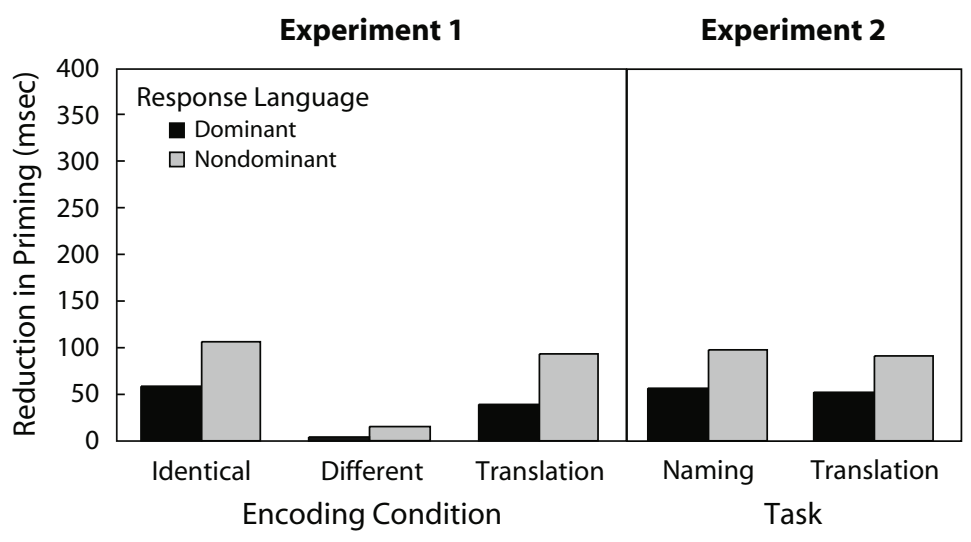

Figure 3. Reductions in priming across a 1-week delay in Experiments 1 and 2. Reductions are measured relative to the 10 -min retention interval.

in picture naming. The contribution of word retrieval processes to priming was greater in the nondominant language, as indicated by stronger priming in translation and identical conditions when responding in the nondominant language. However, the contribution of picture identification priming did not depend on the response language, as indicated by symmetric priming across languages in the different-language naming conditions. This pattern was evident at the short retention interval, replicating our previous research (Francis, Augustini, \& Sáenz, 2003), as well as at the long retention interval.

Facilitation attributable to word retrieval processes decayed faster than facilitation attributable to picture identification processes, whether considered in terms of absolute differences or proportions. The nondominant language exhibited greater loss when considered in absolute terms, but when loss was considered as a proportion of the immediatecondition facilitation effect, the rate of loss was similar to that of the dominant language. To rule out the simplistic explanation that the difference arises because pictures are less susceptible to forgetting than words, in Experiment 2 comparison conditions were included in which the stimuli were presented as words that had to be translated. Word comprehension is an identification process as well as one involving words rather than pictures.

\section{EXPERIMENT 2}

Facilitation elicited by identical repetitions in picture naming and translation was measured at 10-min and 1-week retention intervals in Experiment 2. As explained in the introduction, concept-mediated translation requires both word comprehension and word retrieval processes. Thus, translation shares word retrieval processes with picture naming but also requires word comprehension processes not shared with picture naming, which instead requires picture identification. The contribution of word retrieval to repetition priming in picture naming and translation is essentially equivalent, based on a previous study showing symmetric priming between picture nam- ing and translation (Francis, Augustini, \& Sáenz, 2003). Therefore, any differences in priming magnitude between picture naming and translation can be attributed to differences between picture identification processes, in the case of picture naming, and word comprehension processes, in the case of translation. Estimates of word comprehension contributions to repetition priming translation at short and long delays can be obtained by subtracting the estimates of word retrieval contributions obtained in Experiment 1 from the identical translation repetition priming values in Experiment 2. Experiment 2 incorporated essentially the same materials and timing structure as Experiment 1 to allow fitting a linear model based on data from both experiments. Replication of the identical picture naming conditions allowed a comparison of participant proficiency across experiments.

\section{Method}

Participants. The participants were 72 Spanish-English bilinguals (32 men, 40 women) recruited from the same population as in Experiment 1. They ranged in age from 17 to 48 (median, 20) and all reported Hispanic ethnicity. Twelve additional individuals began the protocol, but 6 were excluded because they failed to show up for the second session and 6 because of low accuracy (less than $50 \%$ ) in English or Spanish. According to the self-report questionnaire, $86.1 \%$ of the participants had learned Spanish first, $5.6 \%$ had learned English first, and 8.3\% had learned Spanish and English simultaneously from early childhood. The median age of second language exposure was 5 years. According to self-ratings of relative proficiency, $52.8 \%$ were classified as English dominant and 47.2\% as Spanish dominant. Over the preceding month, they reported using English $46.8 \%$, Spanish $40.4 \%$, and a mixture of both languages $12.5 \%$ of the time.

Materials. The 288 experimental stimuli were the 280 items used in Experiment 1, plus 8 additional items. Items were randomly assigned to 12 sets of 24 , and sets were rotated through the 12 conditions across participants using a Latin square to control for specificitem effects.

Design and Procedure. The experiment had a 2 (task) $\times 2$ (response language) $\times 2$ (retention interval) within-subjects factorial design with new-item control conditions for each task $\times$ response language combination. The tasks were picture naming and translation, the response languages were English and Spanish, and the retention intervals were immediate $(10 \mathrm{~min})$ or delayed (1 week). For repeated items, task and response language were held constant from 
Table 4

Test Phase Response Times (RT, in Milliseconds) and Error Rates (\%) in Experiment 2

\begin{tabular}{|c|c|c|c|c|}
\hline \multirow[b]{2}{*}{ Task } & \multicolumn{2}{|c|}{ RTs } & \multicolumn{2}{|c|}{ Error Rate } \\
\hline & L1 & L2 & L1 & L2 \\
\hline \multicolumn{5}{|l|}{ New Items } \\
\hline Picture naming & 1,168 & 1,308 & 11.8 & 19.3 \\
\hline Translation & 1,409 & 1,397 & 15.8 & 20.8 \\
\hline \multicolumn{5}{|c|}{ Immediate Retention Interval (10 $\mathrm{min})$} \\
\hline Picture naming & 931 & 978 & 7.5 & 17.9 \\
\hline Translation & 1,109 & 1,061 & 13.0 & 19.0 \\
\hline \multicolumn{5}{|c|}{ Delayed Retention Interval (1 week) } \\
\hline Picture naming & 989 & 1,078 & 7.5 & 17.3 \\
\hline Translation & 1,162 & 1,153 & 13.1 & 17.4 \\
\hline
\end{tabular}

encoding to test. The procedure (including instructions, tasks, trial structure, and counterbalancing) was the same as for Experiment 1, except that the test phase had four blocks of 72 trials, with one block for each of the four task-language combinations.

\section{Results}

Data processing. Data were processed in the same manner as in Experiment 1. Out of a total of 288 test phase trials, on average $15.0 \%(S D=5.6 \%)$ were removed as naming response errors, $1.4 \%$ as machine timing errors, $7.8 \%$ as spoiled trials, and $4.6 \%$ as outliers. On average, $71.1 \%$ of the test phase trials were retained for the RT analysis, a mean of 17 items per condition per participant.

Encoding phase. Encoding phase response times and error rates are given in Table 2 and were analyzed in the same manner as in Experiment 1. RTs and error rates followed the same patterns as in Experiment 1, with all main effects and interactions being statistically significant $(p s<.01)$.

Test phase. Test phase RTs and error rates are shown in Table 4 as a function of task, response language, and retention interval. New-item RTs followed the same pattern as in the encoding phase but were longer. Repetition priming effects are illustrated in Figure 4 as a function of task, response language, and retention interval. Using a Bonferroni correction with a family-wise error rate of $\alpha=.05$, priming effects for all 8 priming conditions were statistically significant.

The subtracted priming scores were analyzed using a 2 (task) $\times 2$ (response language) $\times 2$ (retention interval) repeated measures ANOVA. Priming was numerically stronger for translation than for picture naming, but this effect was only marginally significant $[F(1,71)=3.00$, $\left.M S_{\mathrm{e}}=68,306, p=.088\right]$. Similarly, priming was numerically stronger in the nondominant language than in the dominant language, but this effect was only marginally significant $\left[F(1,71)=3.08, M S_{\mathrm{e}}=91,804, p=.083\right]$. The effect of response language did not differ across tasks $\left[F(1,71)=1.08, M S_{\mathrm{e}}=99,771, p=.303\right]$.

Reductions in priming across the delay are illustrated in Figure 3. Overall, priming decreased across the 1-week delay, as indicated by a main effect of retention interval $\left[F(1,71)=51.54, M S_{\mathrm{e}}=15,867, p<.001\right]$. Contrary to expectations, priming did not decrease more across the delay for translation than for picture naming $[F(1,71)=$ $\left.0.14, M S_{\mathrm{e}}=11,341, p=.706\right]$. However, there was a marginally significant interaction of response language and retention interval, indicating a greater reduction in priming across the delay for conditions in which responses were given in the nondominant language $[F(1,71)=3.33$, $\left.M S_{\mathrm{e}}=18,019, p<.072\right]$. The three-way interaction of task, language, and retention interval was not significant $\left[F(1,71)=0.00, M S_{\mathrm{e}}=18,356, p<.960\right]$.

\section{Discussion}

As in Experiment 1 and previous research (Brown et al., 1996; Cave \& Squire, 1992; Mitchell \& Brown, 1988), priming of picture naming was strong but attenuated after a 1-week delay. Translation also exhibited facilitation at the short retention interval as in previous research (Francis et al., 2002; Francis \& Durán, 2005; Francis \& Gallard, 2005; Francis, Tokowicz, \& Kroll, 2003). Priming of translation was substantial but attenuated at the longer retention interval, with a degree of attenuation similar to that observed for picture naming.

Because picture naming and translation share word retrieval processes, any differences in facilitation observed for these tasks would be attributed to differences between picture identification processes of picture naming and word comprehension processes of translation. Priming for translation was numerically stronger than priming for picture naming, suggesting a greater priming contribution from word comprehension than from picture identification, but this effect was only marginally significant. The similar effects of retention interval for picture naming and translation indicate that the processes not shared (i.e., word comprehension and picture identification processes) do not differ in their degree of attenuation across the delay. If it is assumed that the priming of word retrieval processes is of similar magnitude to that observed in Experiment 1, then it appears that picture identification and word comprehension both exhibited facilitation that did not decline across the week delay. Effects of the delay were strikingly similar in magnitude to those observed for conditions involving word retrieval in Experi- 


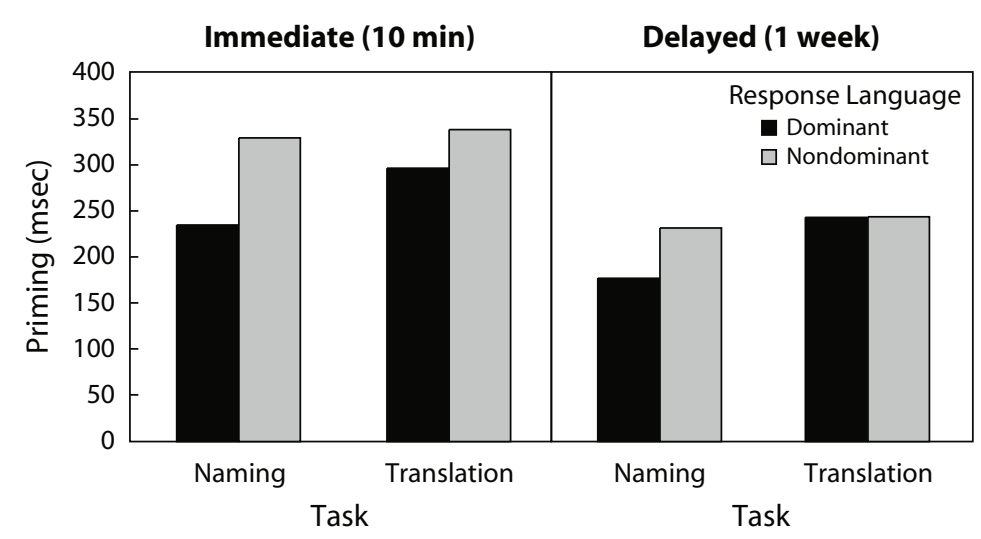

Figure 4. Priming effects in Experiment 2 as a function of retention interval, task, and response language. Priming is measured relative to new item response times in the test phase. In all cases, the encoding and test tasks were identical.

ment 1 . The contributions of picture identification, word comprehension, and word retrieval to repetition priming are further clarified through the model analysis described in the following section.

\section{A SIMPLE MODEL OF REPETITION PRIMING PROCESSES}

A series of simple models was used to estimate contributions of component processes of picture naming and translation to repetition priming and to test for differences across retention intervals and languages. As explained above, predictions of priming for each experimental condition were derived on the basis of the processes shared by the study task and test task, listed in Table 1. Contributions of the component processes in each condition were expressed in linear equations. Across the two experiments, there were 10 encoding conditions, each tested at 2 retention intervals. A set of linear models addressed the three key questions: whether the transfer-appropriate processing relations hold at both retention intervals, whether forgetting rates differ for identification and production processes, and whether priming contributions or forgetting rates depend on language proficiency.

\section{Transfer-Appropriate Processing Assumptions}

If the transfer-appropriate processing assumptions of this study are reasonable, a model based solely on contributions of the processes to priming ought to fit at any retention interval. The basic model had parameters corresponding to the priming contributions of the five processes: picture identification (PI), dominant-language word comprehension (WC1), nondominant-language word comprehension (WC2), dominant-language word retrieval (WR1), and nondominant-language word retrieval (WR2). The model was fit separately to the immediate data and to the delayed data. This 5-parameter model fit well for both the immediate data $\left(R M S_{\mathrm{e}}=\right.$ $10.0 \mathrm{msec})$ and the delayed data $\left(R M S_{\mathrm{e}}=11.1 \mathrm{msec}\right)$, and model fit was very similar for the two retention intervals.

\section{Forgetting}

A forgetting parameter was assigned to each process to represent the proportion by which the priming effect decreased from the immediate to the delayed retention interval. The forgetting parameter $(f)$ was assigned such that $P R_{\text {delayed }}=P R_{\text {immediate }} *(1-f)$ for each process, where $P R$ represents the magnitude of the priming effect. The initial full model had 5 process contribution parameters and 5 corresponding forgetting parameters, or 10 parameters in all. Because 20 priming effects were measured, there were 20 free data points, and 10 degrees of freedom in the full model. This model fit relatively well $\left(R M S_{\mathrm{e}}=\right.$ 10.6). (Parameter estimates for the full model are given in Table 1.)

The effects of retention interval on the contributions of the five processes to priming were examined by making restrictions relative to the full model, specifically by setting $f$ to zero or setting values of $f$ equal across processes. Fits of the restricted models were compared to the fit of the full model to determine whether the restrictions significantly reduced fit. For each restriction, an $F$ test for the effect of the restriction is reported, along with the $R M S_{\mathrm{e}}$ of the corresponding restricted model. Setting word retrieval forgetting parameters to zero decreased fit relative to the full model in both the dominant language $[F(1,10)=9.15$, $\left.p=.013, R M S_{\mathrm{e}}=14.6\right]$ and the nondominant language $\left[F(1,10)=48.88, p<.001, R M S_{\mathrm{e}}=25.7\right]$, indicating that priming contributions of word retrieval processes in both languages decreased over the 1-week delay.

However, setting the forgetting parameters to zero for picture identification or word comprehension (in either language) did not decrease fit relative to the full model. In fact, a model with all three restrictions did not reduce fit significantly relative to the full model $[F(3,10)=$ $\left.0.40, p=.757, R M S_{\mathrm{e}}=11.2\right]$, indicating that the contributions of picture identification and word comprehension processes did not decrease reliably over the 1-week 
delay. When the model was further restricted by setting forgetting parameters for word retrieval in the dominant and nondominant languages to be equal, the fit was not significantly reduced relative to the previous model $\left[F(1,13)=0.66, p=.431, R M S_{\mathrm{e}}=11.47\right]$ or relative to the full model $[F(4,10)=0.44, p=.777]$. The parameter estimates derived and the predictions of priming from this 6-parameter restricted model are shown in Table 1.

\section{Language Proficiency}

Contributions to priming were compared across languages by making additional restrictions relative to the 6-parameter restricted model. Setting word comprehension contributions equal for the two languages significantly reduced fit $\left[F(1,14)=13.46, p=.003, R M S_{\mathrm{e}}=\right.$ 16.1]. Setting word retrieval contributions to be equal across languages also reduced fit $[F(1,14)=95.63, p<$ $\left..001, R M S_{\mathrm{e}}=32.1\right]$. (These restrictions were also significant when measured relative to the full model.) As expected, the contributions of word comprehension and word retrieval were greater in the nondominant language than in the dominant language. Because the preceding language restrictions significantly decreased the fit of the model, the 6-parameter model was retained. As explained in the preceding paragraph, forgetting rates did not differ across languages.

\section{GENERAL DISCUSSION}

\section{Summary of Main Findings}

In Experiments 1 and 2, repetition priming for picture naming was observed at both the 10-min and 1-week retention intervals, replicating findings of durable repetition priming in previous research (Brown et al., 1996; Cave, 1997; Cave \& Squire, 1992; Mitchell \& Brown, 1988; Mitchell et al., 1990). Priming of picture naming using picture naming in the nontarget language and translation to the target language as encoding tasks in Experiment 1 indicated that both picture identification and word retrieval processes contributed to priming in picture naming. These findings were consistent with our past work (Francis, 1998; Francis, Augustini, \& Sáenz, 2003; Francis et al., 2002). Both of these priming contributions were reliable even at the 1-week retention interval, although the facilitation attributable to speeded word retrieval decreased.

Experiment 2 replicated previous findings of repetition priming in translation at a short retention interval (Francis et al., 2002; Francis \& Durán, 2005; Francis \& Gallard, 2005; Francis, Tokowicz, \& Kroll, 2003), and demonstrated for the first time the durability of this repetition priming across a 1-week retention interval. In Experiment 2 , the repetition priming effect observed with identical translation repetition is far greater than the contribution that can be attributed to word retrieval, indicating contributions of word comprehension processes to repetition priming (as in Francis et al., 2002; Francis \& Durán, 2005; Francis \& Gallard, 2005). Both contributions were reliable even at the 1-week retention interval, although the facilitation attributable to speeded word retrieval decreased, as shown in the model analysis.

\section{Mechanisms of Facilitation and Repetition Priming}

The patterns of observed RTs and the endurance of the priming effects across time constrain the plausible mechanisms of repetition priming. First, the facilitation observed in partial repetition conditions of Experiment 1 rules out explanations of identical priming that involve a qualitative change in processing route (e.g., from conceptmediated to direct) or strengthening a simple stimulusresponse association. Instead, the component processes of picture identification and word retrieval are executed more quickly when repeated. Second, the long-lasting facilitation effects observed with identical repetitions in picture naming and translation are inconsistent with an explanation that they are caused by a temporary increase in activation of the stimulus word, concept, or response word. Similarly, the contributions of picture identification, word comprehension, and word retrieval processes at the 1-week interval are inconsistent with the notion that they result from a temporary increase in activation. Instead, these effects reflect sustained learning (Cave, 1997; Mitchell \& Brown, 1988). Practice of comprehension or production of specific words produces long-term learning even when only a single experimental episode is added to an individual's history of preexperimental comprehension and production exposures.

\section{Effects of Process and Task Difficulty on Degree of Facilitation}

One implication of the transfer-appropriate processing logic used in this study is that more difficult processes should exhibit stronger priming. This assertion is not the same as to say that tasks with longer mean RTs will exhibit larger difference scores. Tasks with longer RTs usually do exhibit larger priming effects under conditions of identical repetition, but we argue that it is because tasks with longer RTs have a profile of component processes that are slower, or less well learned. The magnitude of repetition priming effects is not simply a monotonic function of the baseline RT of the test task, and counterexamples are evident in the partial repetition conditions. For example, in Experiment 1, the contribution of picture identification to facilitation in picture naming did not differ according to the final response language, even though RTs were longer in the nondominant language (as in Francis, Augustini, \& Sáenz, 2003). However, this finding is consistent with the expectation that priming magnitude will be monotonically related to the difficulty of the repeated processes, as are language-proficiency effects on word retrieval and word comprehension.

Contributions of word retrieval processes to facilitation were stronger when responses were made in the more difficult nondominant language (as in Francis, Augustini, \& Sáenz, 2003; Francis et al., 2002; Francis \& Gallard, 2005), paralleling effects of word frequency (Wheeldon \& Monsell, 1992) and age of word acqui- 
sition (Barry, Hirsh, Johnston, \& Williams, 2001) on word production priming in picture naming. Similarly, the model analysis showed that contributions of word comprehension processes to facilitation in translation were stronger in the nondominant language. Based on the model estimates, priming of word comprehension in the dominant language was similar to the priming of picture identification.

\section{Nature of Forgetting or Loss of Facilitation in Implicit Memory}

The relative contributions of picture identification and word retrieval to repetition priming changed across retention intervals. The magnitude of priming from practice of picture identification processes did not change substantially across the retention interval, but priming based on word retrieval decreased substantially and reliably. Although production had a bigger benefit from repetition, the benefits of practice were better retained across time for identification and comprehension processes. However, forgetting across a 1-week interval was not a monotonic function of the initial priming magnitude. Word comprehension in the nondominant language and word retrieval in the dominant language made similar contributions to facilitation at $10 \mathrm{~min}$, but their forgetting rates differed substantially, whether considered in terms of absolute or proportional loss. The contribution of word comprehension to facilitation is larger for the nondominant language than for the dominant language, but the forgetting rates for these two processes are equivalent, whether considered in absolute or proportional terms. (The latter result also indicates that forgetting is not a monotonic function of process difficulty.) Finally, word retrieval contributions to priming were stronger in the nondominant language, but the proportional forgetting rates were equivalent.

These dissociations support a distinction between identification and production forms of repetition priming. Gabrieli has promoted this distinction as fundamental in the functional organization of implicit memory and showed that it predicted which forms of priming were impaired in early Alzheimer's disease or affected by attentional manipulations (Gabrieli et al., 1999). However, in contrast to Gabrieli's research, in the present study picture naming was not considered an identification task, but rather a complex task with dissociable identification and production components. Thus, the distinction was made within rather than across repetition priming paradigms. In Experiment 2, the model estimates indicate that repetition priming in translation attributable to word retrieval exhibited a substantial decrease across retention intervals, whereas comprehension processes did not. This pattern extends the within-task dissociation of identification and production forms of priming to translation.

It is not clear why the forgetting rates differ for identification, comprehension, and production components. One possibility is that these differences stem from differences in preexperimental learning for the different processes. In explicit memory tests, diverse item types show similar forgetting rates if equally well learned, but less well-learned items show faster forgetting (Slamecka \& McElree, 1983; Wixted, 2004). Extending this idea to the component processes of word translation, if production is less well learned than identification or comprehension, then production should exhibit faster forgetting; this is what we observed. This explanation seems reasonable for translation, but extending it to picture identification processes is problematic, because participants had no prior exposure to the experimental pictures. Also, when comparing dominant and nondominant language performance in which production in the nondominant language is clearly less well learned, the rates of decay for word retrieval are equivalent. Therefore, the degree of preexperimental learning does not adequately explain the patterns of forgetting observed.

A second possibility is that the forgetting rate differences arise because production processes are more affected by competition or interference processes than are identification and comprehension processes. This is the explanation given by Gabrieli et al. (1999) for attention manipulations affecting production but not affecting identification forms of repetition priming. During a 1-week retention interval, a participant will listen to, read, and speak thousands of words. These episodes of retrieving other words may reduce the retrievability of the experimental words when producing them at test but would not be expected to affect comprehension. For the pictures, similar exposures during the retention interval seem unlikely, so there would be little basis for interference. The idea that differences in competition underlie the differences in forgetting rates does not appear to conflict with the findings. However, strong support for this explanation would require a focused manipulation of identification, comprehension, and production exposures to potentially competing stimuli.

\section{Conclusions}

Although previous research demonstrated the endurance of repetition priming for picture naming across long retention intervals, it did not decompose the processes contributing to the endurance, or the attenuation of priming across these intervals. The present study shows that both picture identification and word retrieval processes contribute to the durability of repetition priming in picture naming, with both sets of processes exhibiting substantial facilitation across a 1-week retention interval. Repetition priming for translation also lasts for at least a week, and both word comprehension and word retrieval processes of translation contribute to priming across a 1-week retention interval. More importantly, the relative contributions of the component processes changed across the retention intervals. Priming contributions of picture identification and word comprehension processes remained relatively stable over time, whereas contributions of word retrieval processes diminished. Thus, word retrieval was more sensitive to the retention interval manipulation than were picture identification and word comprehension processes.

The nature of forgetting in repetition priming or in implicit memory more generally has not been explored as thoroughly as forgetting in explicit memory, nor is it clear 
that it is driven by the same mechanisms. The present study shows that the rate of loss is not simply a percentage of the repetition priming effect size, but that contributions of different processes to the repetition priming effect do change across time. Models of forgetting, or loss of facilitation, in repetition priming must therefore accommodate different rates of loss for different components or processes. The present results support the dissociation between identification and production forms of repetition priming. However, the bases of priming for a given paradigm will depend on the encoding task, the retention interval, and the language proficiency of the research participants.

\section{AUTHOR NOTE}

This research was supported by National Institutes of Health Grant MH61765 to the first author. We thank Casey A. Gutierrez for his assistance with Experiment 2. Experiment 1 was completed as a senior honors thesis by the second author, who presented the results at the Llano Estacado Undergraduate Psychology Research Conference and at the Encuentro InterEstudiantil de Psicología del Estado de Chihuahua. The entire project was presented at the 44th Annual Meeting of the Psychonomic Society (2003). Correspondence concerning this article should be addressed to W. S. Francis, Department of Psychology, University of Texas at El Paso, 500 West University Avenue, El Paso, TX 79968 (e-mail:wfrancis@utep.edu).

Note-This article was accepted by the previous editorial team, when Colin M. MacLeod was Editor.

\section{REFERENCES}

Aвbate, M. S. (1984). Pictures please: An articulation supplement. Tucson, AZ: Communication Skill Builders.

Barry, C., Hirsh, K. W., Johnston, R. A., \& Williams, C. L. (2001). Age of acquisition, word frequency, and the locus of repetition priming of picture naming. Journal of Memory \& Language, 44, 350-375.

Biederman, I., \& Cooper, E. E. (1991). Priming contour-deleted images: Evidence for intermediate representations in visual object recognition. Cognitive Psychology, 23, 393-419.

Brown, A. S., Jones, T. C., \& Mitchell, D. B. (1996). Single and multiple test repetition priming in implicit memory. Memory, $\mathbf{4}$, 159-173.

Carroll, M., Byrne, B., \& Kirsner, K. (1985). Autobiographical memory and perceptual learning: A developmental study using picture recognition, naming latency, and perceptual identification. Memory \& Cognition, 13, 273-279.

CAVE, C. B. (1997). Very long-lasting priming in picture naming. Psychological Science, 8, 322-325.

CAve, C. B., Bost, P. R., \& СовB, R. E. (1996). Effects of color and pattern on implicit and explicit picture memory. Journal of Experimental Psychology: Learning, Memory, \& Cognition, 22, 639-653.

CAVE, C. B., \& SQuire, L. R. (1992). Intact and long-lasting repetition priming in amnesia. Journal of Experimental Psychology: Learning, Memory, \& Cognition, 18, 509-520.

Chen, H. C., \& Leung, Y. S. (1989). Patterns of lexical processing in a nonnative language. Journal of Experimental Psychology: Learning, Memory, \& Cognition, 15, 316-325.

Cohen, J. D., MacWhinney, B., Flatt, M., \& Provost, J. (1993). PsyScope: An interactive graphic system for designing and controlling experiments in the psychology laboratory using Macintosh computers. Behavior Research Methods, Instruments, \& Computers, 25, 257-271.

De Groot, A. M. B., \& Роот, R. (1997). Word translation at three levels of proficiency in a second language: The ubiquitous involvement of conceptual memory. Language Learning, 47, 215-264.

Durso, F. T., \& Johnson, M. K. (1979). Facilitation in naming and categorizing repeated pictures and words. Journal of Experimental Psychology: Human Learning \& Memory, 5, 449-459.
EbBINGHaus, H. (1885). Über das Gedächtnis: Untersuchungen zur experimentellen Psychologie. Leipzig: Duncker \& Humblot. [Reprinted as H. Ebbinghaus (1964). Memory: A contribution to experimental psychology (H. A. Ruger \& C. E. Bussenius, Trans.). New York: Dover.]

Francis, W. S. (1998). Components of repetition priming in picture naming: Emphasizing "processes" in transfer-appropriate processing. Abstracts of the Psychonomic Society, 3, 63.

FranCIS, W. S. (1999). Cognitive integration of language and memory in bilinguals: Semantic representation. Psychological Bulletin, 125, 193-222.

Francis, W. S. (2005). Bilingual semantic and conceptual representation. In J. F. Kroll \& A. M. B. De Groot (Eds.), Handbook of bilingualism: Psycholinguistic approaches (pp. 251-267). Oxford: Oxford University Press.

Francis, W. S., Augustini, B. K., \& Sáenz, S. P. (2003). Repetition priming in picture naming and translation depends on shared processes and their difficulty: Evidence from Spanish-English bilinguals. Journal of Experimental Psychology: Learning, Memory, \& Cognition, 29, 1283-1297.

Francis, W. S., Corral, N. I., Arzate, J. C., Luévano, G., Jones, M. L., \& Regalado, P. (2002). Decomposition of priming components in picture naming and translation. Abstracts of the Psychonomic Society, 7, 32.

Francis, W. S., \& Durán, G. (2005). Decomposition of repetition priming processes in bilingual word translation. Abstracts of the Psychonomic Society, 10, 134-135.

Francis, W. S., \& Gallard, S. L. K. (2005). Concept mediation in trilingual translation: Evidence from response time and repetition priming patterns. Psychonomic Bulletin \& Review, 12, 1082-1088.

Francis, W. S., Tokowicz, N., \& Kroll, J. F. (2003, May). Translation priming as a function of bilingual proficiency and item difficulty. Poster presented at the 4th International Symposium on Bilingualism, Tempe, AZ.

Franks, J. J., Bilbrey, C. W., Lien, K. G., \& McNamara, T. P. (2000). Transfer-appropriate processing (TAP) and repetition priming. Memory \& Cognition, 28, 1140-1151.

Gabrieli, J. D. E., Vaidya, C. J., Stone, M., Francis, W. S., ThompsonSchill, S. L., Fleischman, D. A., et al. (1999). Convergent behavioral and neuropsychological evidence for a distinction between identification and production forms of repetition priming. Journal of Experimental Psychology: General, 128, 479-498.

GRAF, P., \& MANDLER, G. (1984). Activation makes words more accessible, but not necessarily more retrievable. Journal of Verbal Learning \& Verbal Behavior, 23, 553-568.

Hernandez, A. E., \& Reyes, I. (2002). Within- and between-language priming differ: Evidence from repetition of pictures in SpanishEnglish bilinguals. Journal of Experimental Psychology: Learning, Memory, \& Cognition, 28, 726-734.

Johnson, C. J., Paivio, A., \& Clark, J. M. (1996). Cognitive components of picture naming. Psychological Bulletin, 120, 113-139.

Kroll, J. F., \& SteWART, E. (1994). Category interference in translation and picture naming: Evidence for asymmetric connections between bilingual memory representations. Journal of Memory \& Language, 33, 149-174.

KUČERA, H., \& FRANCIS, W. N. (1967). A computational analysis of present-day American English. Providence, RI: Brown University Press.

La Heis, W., Hooglander, A., Kerling, R., \& van der Velden, E. (1996). Nonverbal context effects in forward and backward word translation: Evidence for concept mediation. Journal of Memory \& Language, 35, 648-665.

Lee, M. W., \& Williams, J. N. (2001). Lexical access in spoken word production by bilinguals: Evidence from the semantic competitor priming paradigm. Bilingualism: Language \& Cognition, 4, 233-248.

Levelt, W. J. M. (1989). Speaking: From intention to articulation. Cambridge, MA: MIT Press.

Miller, N. A., \& Kroll, J. F. (2002). Stroop effects in bilingual translation. Memory \& Cognition, 30, 614-628.

Mitchell, D. B., \& Brown, A. S. (1988). Persistent repetition priming in picture naming and its dissociation from recognition memory. 
Journal of Experimental Psychology: Learning, Memory, \& Cognition, 14, 213-222.

Mitchell, D. B., Brown, A. S., \& Murphy, D. R. (1990). Dissociations between procedural and episodic memory: Effects of time and aging. Psychology \& Aging, 5, 264-276.

Monsell, S., Matthews, G. H., \& Miller, D. C. (1992). Repetition of lexicalization across languages: A further test of the locus of priming. Quarterly Journal of Experimental Psychology, 44A, 763-783.

Morris, C. D., Bransford, J. D., \& FranKs, J. J. (1977). Levels of processing versus transfer appropriate processing. Journal of Verbal Learning \& Verbal Behavior, 16, 519-533.

MorTON, J. (1979). Facilitation in word recognition: Experiments causing change in the logogen model. In P. A. Kolers, M. E. Wrolstad, \& H. Bouma (Eds.), Processing of visible language: Vol. 1 (pp. 259268). New York: Plenum.

Potter, M. C., \& Faulconer, B. A. (1975). Time to understand pictures and words. Nature, 253, 437-438.

Potter, M. C., So, K.-F., von Eckardt, B., \& Feldman, L. B. (1984). Lexical and conceptual representation in beginning and proficient bilinguals. Journal of Verbal Learning \& Verbal Behavior, 23, 23-38.

Roediger, H. L., III, \& Blaxton, T. A. (1987). Effects of varying modality, surface features, and retention interval on priming in wordfragment completion. Memory \& Cognition, 15, 379-388.

SCHACTER, D. L. (1987). Implicit memory: History and current status. Journal of Experimental Psychology: Learning, Memory, \& Cognition, 13, 501-518.

Schacter, D. L. (1992). Priming and multiple memory systems: Perceptual mechanisms of implicit memory. Journal of Cognitive Neuroscience, 4, 244-256.

Sholl, A., Sankaranarayanan, A., \& Kroll, J. F. (1995). Transfer between picture naming and translation: A test of asymmetries in bilingual memory. Psychological Science, 6, 45-49.

SlameCKa, N. J., \& McElree, B. (1983). Normal forgetting of verbal lists as a function of their degree of learning. Journal of Experimental Psychology: Learning, Memory, \& Cognition, 9, 384-397.

Smith, M. C., \& Magee, L. E. (1980). Tracing the time course of picture-word processing. Journal of Experimental Psychology: General, 109, 373-392.

SNOdgrass, J. G. (1984). Concepts and their surface representations. Journal of Verbal Learning \& Verbal Behavior, 23, 3-22.

SNODGRASS, J. G., \& VANDERWART, M. (1980). A standardized set of 260 pictures: Norms for name agreement, image agreement, familiarity, and visual complexity. Journal of Experimental Psychology: Human Learning \& Memory, 6, 174-215.

Stankiewicz, B. J., Hummel, J. E., \& Cooper, E. E. (1998). The role of attention in priming for left-right reflections of object images: Evidence for a dual representation of object shape. Journal of Experimental Psychology: Human Perception \& Performance, 24, 732-744.

Theios, J., \& Amrhein, P. C. (1989). Theoretical analysis of the cognitive processing of lexical and pictorial stimuli: Reading, naming, and visual and conceptual comparisons. Psychological Review, 96, 5-24.
Thompson-Schill, S. L., \& Gabrieli, J. D. E. (1999). Priming of visual and functional knowledge on a semantic classification task. Journal of Experimental Psychology: Learning, Memory, \& Cognition, 25, 41-53.

Townsend, J. T., \& Schweickert, R. (1989). Toward the trichotomy method of reaction times: Laying the foundation of stochastic mental networks. Journal of Mathematical Psychology, 33, 309-327.

Tulving, E., \& SChacter, D. L. (1990). Priming and human memory systems. Science, 247, 301-306.

Vaidya, C. J., Kang, E., Iyer, G., Fine, E., Klein, A. L., \& Gabrieli, J. D. E. (1998). Dissociative effects of conceptual task and stimulus format on conceptual priming. Abstracts of the Psychonomic Society, 3, 29 .

Vriezen, E. R., Moscovitch, M., \& Bellos, S. A. (1995). Priming effects in semantic classification tasks. Journal of Experimental Psychology: Learning, Memory, \& Cognition, 21, 933-946.

Weldon, M. S., \& Roediger, H. L., III (1987). Altering retrieval demands reverses the picture superiority effect. Memory \& Cognition, 15, 269-280.

WheELdon, L. R., \& Monsell, S. (1992). The locus of repetition priming of spoken word production. Quarterly Journal of Experimental Psychology, 44A, 723-761.

WiCKENS, T. D. (1998). On the form of the retention function: Comment on Rubin and Wenzel (1996): A quantitative description of retention. Psychological Review, 105, 379-386.

WIXTED, J. T. (2004). On common ground: Jost's (1897) law of forgetting and Ribot's (1881) law of retrograde amnesia. Psychological Review, 111, 864-879.

\section{NOTES}

1. This version of transfer appropriate processing differs from other transfer appropriate processing explanations in the repetition priming literature. For example, other approaches have emphasized the match between data driven and conceptually driven processing at study and test (Roediger \& Blaxton, 1987; Weldon \& Roediger, 1987); the match between domains of semantic representation accessed at study and test (Thompson-Schill \& Gabrieli, 1999; Vriezen, Moscovitch, \& Bellos, 1995), and the match between perceptual representation systems operating at study and test (Schacter, 1992; Tulving \& Schacter, 1990). More generally, the present approach differs from those that define the match between study and test in terms of representations activated, levels of representation for processing, the type of processing, or the stimuli or cues present.

2. Reported analyses are based on the full set of items. However, a secondary set of analyses was performed that excluded all items that could be considered cognates, and the same pattern of means and significant effects emerged.

3. Unexpected but appropriate naming responses were retained for analysis when the response was consistent across repetitions.

(Manuscript received December 15, 2003; revision accepted for publication August 17, 2006.) 